\title{
Hypophosphataemic osteomalacia associated with a malignant tumour of the tibia: report of a case
}

\author{
A. L. WYMAN, F. J. PARADINAS, AND J. R. DALY
}

From the Departments of Endocrinology, Histopathology, and Chemical Pathology, Charing Cross Hospital and Medical School, London W6 8RF

SUMMARY A case of vitamin D resistant hypophosphataemic osteomalacia with glycosuria and aminoaciduria is reported. The course of the disease was dramatically altered by the removal of a bone sarcoma which probably had been growing slowly since the onset of the patient's symptoms five years previously. The histology and electron microscopy of the tumour are described. Three years after the operation the patient remains free of symptoms.

In recent years several cases of osteomalacia with phosphaturia and hypophosphataemia have been reported in association with tumours of bone or soft tissues of uncertain histogenesis. The manner in which the tumours cause osteomalacia is uncertain, but it has been suggested that they may elaborate a humoral substance, possibly a vitamin $\mathrm{D}$ antagonist (Prader et al., 1959).

\section{Case report}

A 44-year-old male teacher was admitted to hospital in January 1969 for surgical treatment of varicose veins. He complained of pains in the feet and difficulty on walking which persisted after the operation. In April 1970 he was readmitted with pains in the shoulders, back, left loin, and ankles. He had a waddling gait and proximal muscle weakness of the legs. An $x$-ray of a small lump in the right tibia was interpreted as a pseudofracture (Fig. 1), but a skeletal survey showed no other lesion or evidence of hyperparathyroidism.

Laboratory investigation disclosed hypophosphataemia: inorganic phosphorus $0 \cdot 27-0.5 \mathrm{mmol} / 1$ (laboratory's reference range $0 \cdot 7-1 \cdot 4$ ), serum calcium

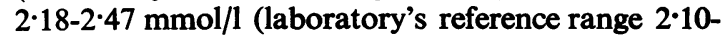
$2 \cdot 65$ ), alkaline phosphatase $13-17 \mathrm{KA}$ units with both bone and liver isoenzymes present on electrophoresis and glycosuria with a low renal threshold for glucose during an otherwise normal glucose tolerance test. Plasma proteins have been normal

Received for publication 28 September 1976

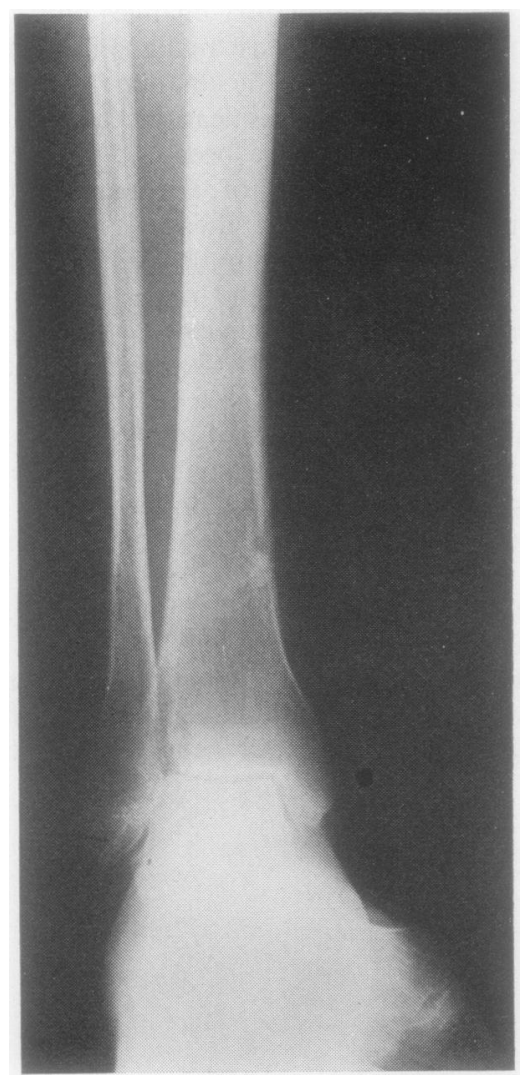

Fig. $1 X$-ray of lesion in right tibia, April 1970. 
throughout. Urinary calcium excretion was normal (3.7-4.4 $\mathrm{mmol} / 24 \mathrm{~h})$ and phosphorus excretion markedly raised (31-38mmol/24h) for the degree of hypophosphataemia. Urinary aminoacid chromatography showed excess lysine, glycine, serine, and cystine. An iliac crest biopsy showed osteomalacia without evidence of hyperparathyroidism (Fig. 2).

Nutritional factors and alimentary disease which could affect vitamin $\mathbf{D}$ or calcium intake were excluded by the clinical history, normal jejunal biopsy, normal faecal fat excretion and xylose absorption, normal serum proteins, and normal values in a wide range of haematological tests, including serum iron, folate, and vitamin $B_{12}$. The urine concentrated normally following pitressin and acidified normally following ammonium chloride. The blood urea was $5.07 \mathrm{mmol} / \mathrm{l}$ and the endogenous creatinine clearance $126 \mathrm{ml} / \mathrm{min}$.

A diagnosis of hypophosphataemic osteomalacia due to renal tubular defect was made and the patient was discharged on $10 \mathrm{~g}$ of bisodium hydrogen phosphate daily. After an initial improvement bone

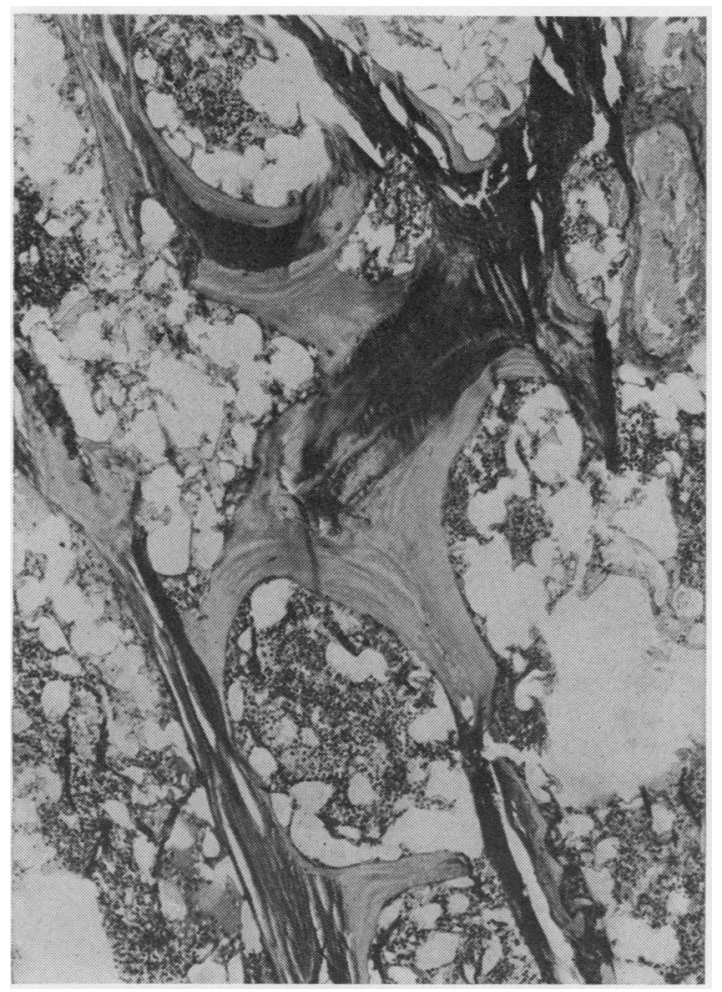

Fig. 2 Undecalcified section of bone showing widened osteoid seams. Iliac crest biopsy. Toluidine blue at pH 2.8, $\times 40$. pain recurred and the dose of phosphate was increased by stages to a maximum of $40 \mathrm{~g}$ daily in May 1971. A short intense course of vitamin D was given for two weeks between June and July 1970. Vitamin $D$ in a dose of 100000 units daily was restarted in July 1971 and continued until shortly before the eventual removal of the tumour (Fig. 3). With this treatment urinary phosphorus excretion increased to $107 \mathrm{mmol} / 24 \mathrm{~h}$ and glycosuria persisted, but the patient improved and in May 1972 he felt 'the best for years'. However, in November 1972 further deterioration occurred and by July 1973 the lesion in the right tibia had become a large osteolytic tumour (Fig. 4) which on biopsy had histological features of malignancy.

A through-knee amputation was carried out in September 1973 (Mr J. Strachan) and all other treatment was discontinued. There was an immediate increase in the serum calcium and phosphate (to $2.55 \mathrm{mmol} / 1$ and $1.4 \mathrm{mmol} / 1$ respectively two weeks postoperatively) and a decrease in the serum alkaline phosphatase (Fig. 3). Plasma proteins remained in the normal range (total $75 \mathrm{~g} / \mathrm{l}$, albumin $48 \mathrm{~g} / \mathrm{l}$ ). The urinary calcium rose to $13.5 \mathrm{mmol} / 24 \mathrm{~h}$ and the phosphorus decreased to $3.1 \mathrm{mmol} / 24 \mathrm{~h}$. However, the serum calcium then continued to rise, reaching $2.9 \mathrm{mmol} / 1$, and the possibility of hyperparathyroidism was considered, but a skeletal survey and serum parathyroid hormone were normal. In February 1974 a hydrocortisone suppression test was carried out (40 mg 8-hourly for 10 days), the serum calcium being $2.75 \mathrm{mmol} / 1$ at the start, $2.80 \mathrm{mmol} / \mathrm{l}$ on the eighth day, and $2.75 \mathrm{mmol} / 1$ on the tenth day.

There was some uncertainty at this stage how best to proceed and an expectant policy was adopted. In subsequent months the serum calcium gradually declined to $2.50 \mathrm{mmol} / 1$. However, inorganic phosphate is declining also $(0.5 \mathrm{mmol} / 1$ by June 1976$)$. The urinary calcium was then $4.4 \mathrm{mmol} / 24 \mathrm{~h}$, the urinary phosphorus $32.0 \mathrm{mmol} / 24 \mathrm{~h}$, and the serum alkaline phosphatase was normal. There was glycosuria of $\frac{1}{4} \%$ but no aminoaciduria. The patient remains free of symptoms without any treatment.

\section{HISTOLOGY OF THE TUMOUR}

The tumour had a heterogeneous macroscopical and microscopical appearance. Most of it had the consistency of a desmoid with gritty areas, but deep within the medullary cavity there were brown soft masses and haemorrhagic cysts. Microscopically most of the tumour consisted of spindle and stellate cells separated by abundant collagen and chondroid matrix (Figs 5 and 6). In a few places there was palisading of nuclei and some osteoid. In the brown areas the tumour was very cellular; there were scattered giant cells of osteoclastic type (Fig. 7) and 


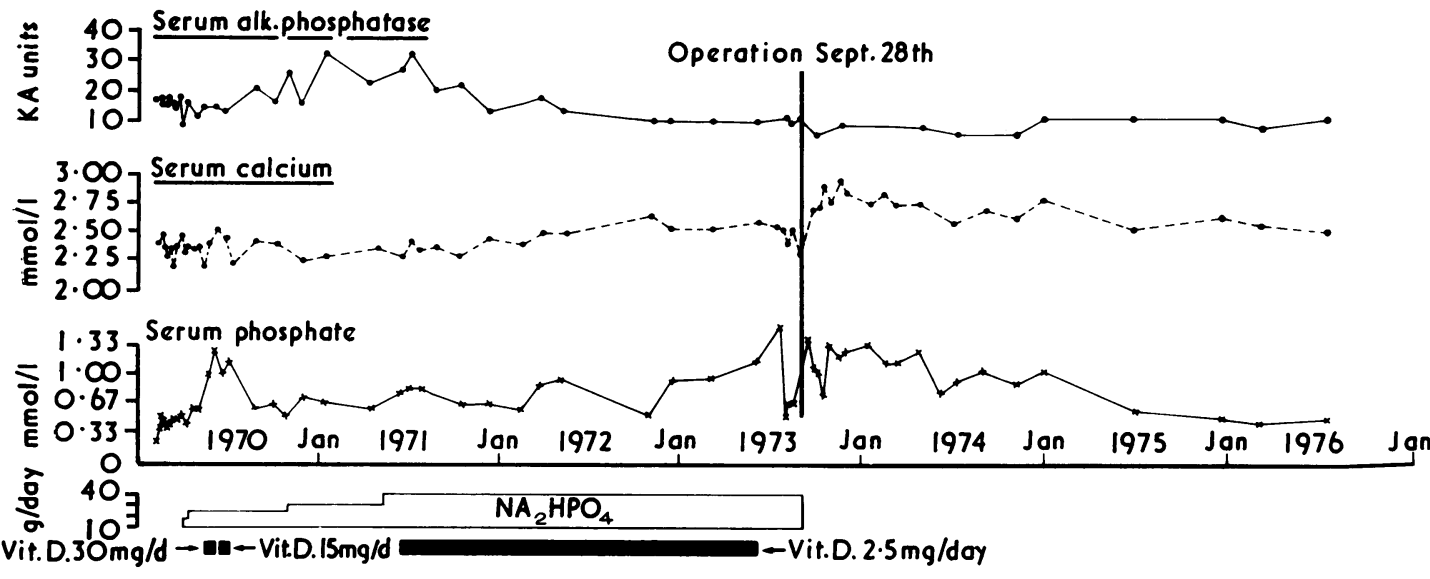

Fig. 3 Biochemical changes and treatment from January 1970 to December 1975.

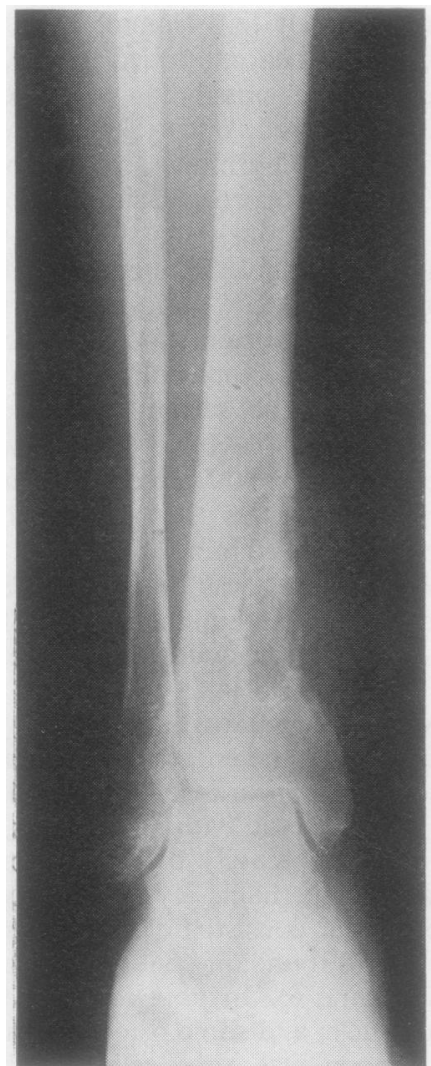

Fig. $4 X$-ray of lesion in right tibia, July 1973.

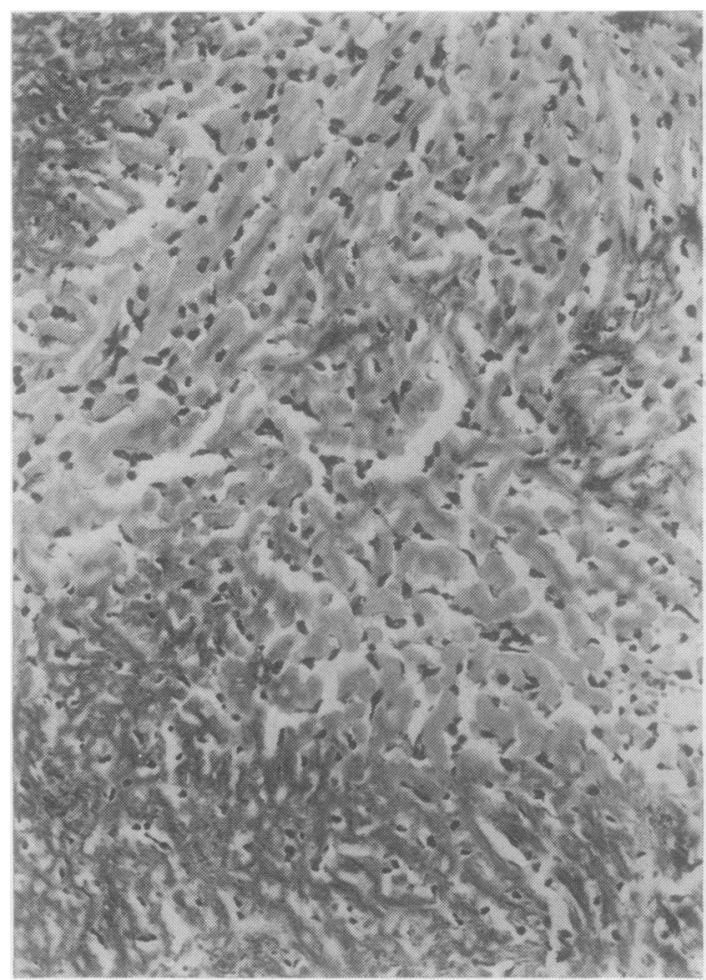

Fig. 5 Area of tumour composed of scanty hyperchromatic spindle cells and abundant collagenised stroma. Haematoxylin and eosin $\times 104$. 


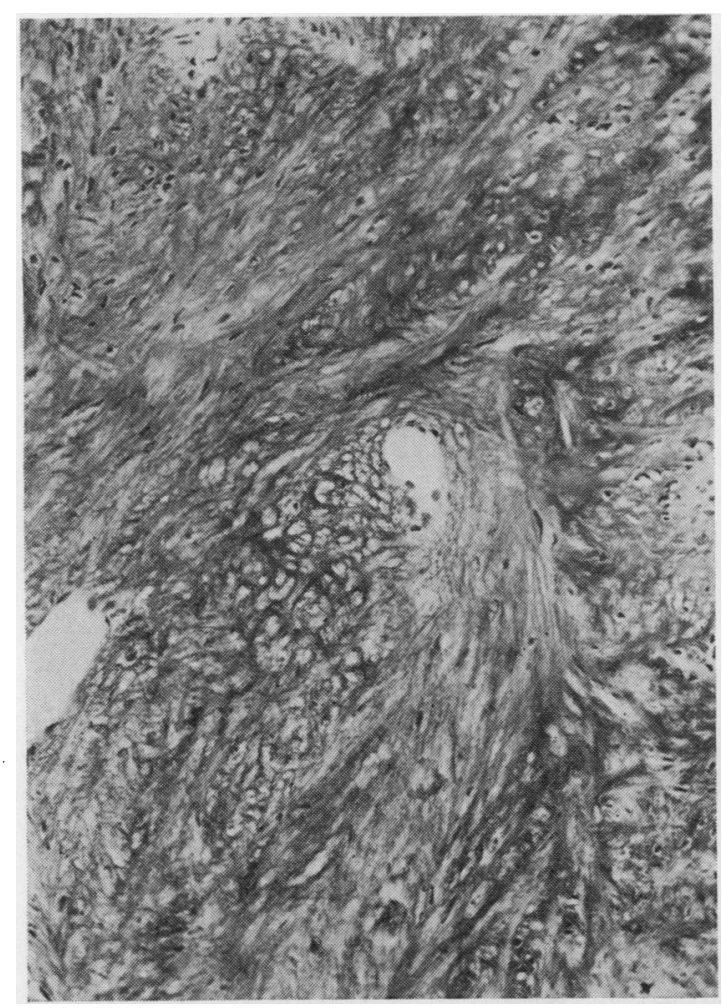

Fig 6

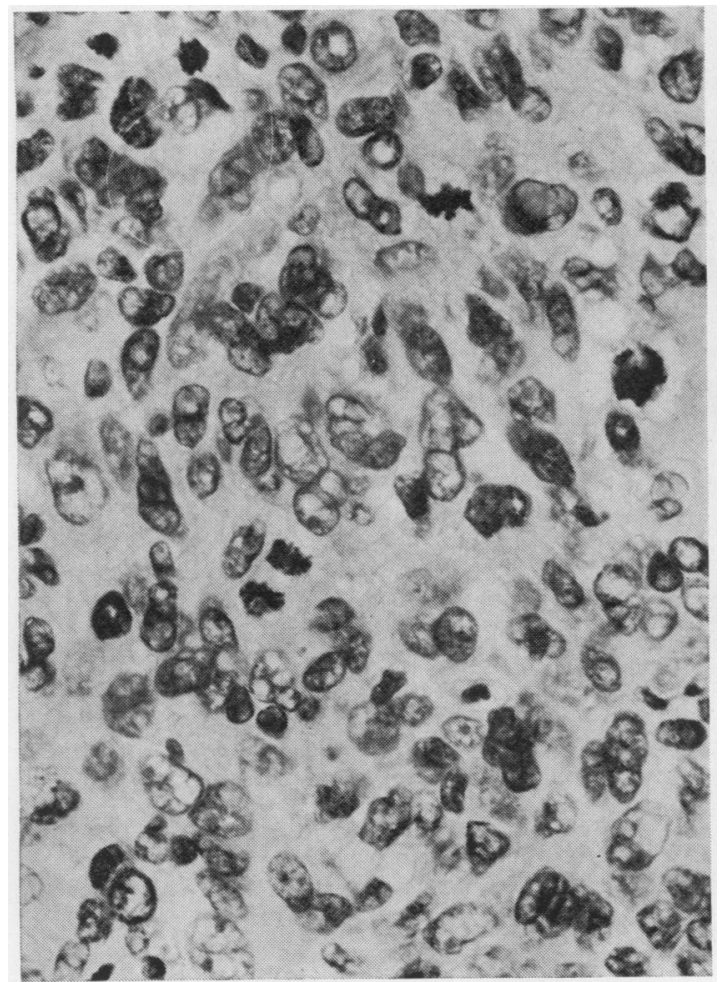

Fig 8

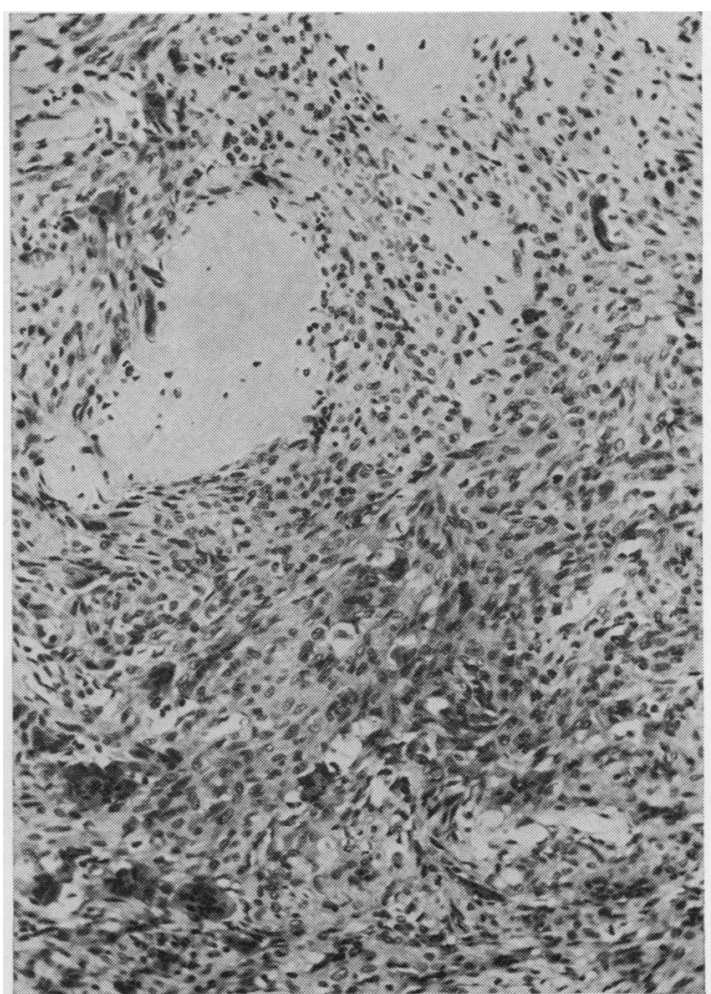

Fig 7

Fig. 6 Tumour composed of chondroid and fibrous matrix with few cells. $H$ and $E \times 104$.

Fig. 7 Very cellular area with a few osteoclasts and island of chondroid matrix. $H$ and $E \times 104$.

Fig. 8 Mitoses and nuclear pleomorphism in the cellular areas. $H$ and $E \times 390$. 

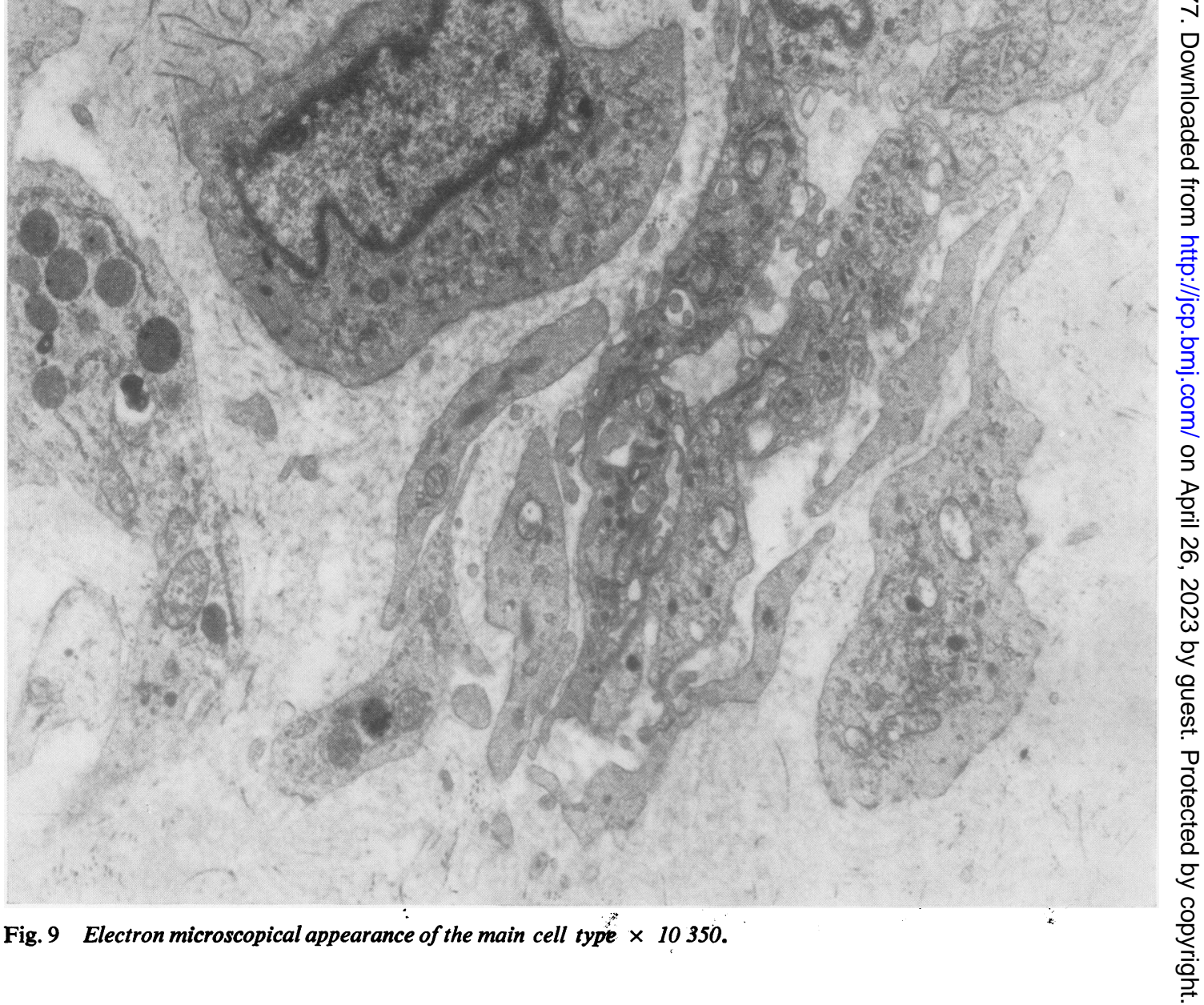
the cellular pleomorphism and mitotic activity (Fig. 8) suggested malignancy which was otherwise confirmed by the locally aggressive behaviour and invasion of surrounding muscles. On electron microscopy the commonest cell seen was spindle or polygonal, with irregular nuclear and cytoplasmic outline (Fig. 9). The cytoplasm contained abundant rough endoplasmic reticulum, Golgi apparatus, and mitochondria. There were occasional smaller darker cells with numerous electron-dense irregular bodies in the cytoplasm. These cells were interpreted as macrophages and the bodies as ferritin bodies. No multinucleated cells were present in the material examined electron microscopically, and neurosecretory granules were not seen in multiple sections. It was concluded that the tumour was a sarcoma of unspecified type.

\section{Discussion}

The patient was at first thought to have the sporadic form of 'vitamin D resistant osteomalacia' first described by McCance (1947), and later reviewed by Dent and Stamp (1971), which is characterised by impaired tubular reabsorption of phosphate. The clinical and biochemical improvement on large doses of bisodium hydrogen phosphate initially seemed to be in accord with this view, but the recurrence of the pain and enlargement of the tibial lesion demanded fresh assessment. This lesion proved to be a sarcoma arising in bone, and its removal resulted in a rise in serum inorganic phosphate despite cessation of phosphate and vitamin D therapy.

To date at least 14 cases of vitamin $D$ resistant osteomalacia or late onset rickets have been reported in association with tumours of bone or soft tissues (Table). In nine cases improvement or cure was observed after removal of the tumour. Eight of these cases were regarded as benign and one as possibly malignant (Massachusetts General Hospital, 1965). In a further case a probably benign tumour was not removed completely and there was no appreciable improvement after surgery (Balsan et al., 1967). In three other cases the tumours were malignant and either there was no improvement after surgery or the tumours were inoperable (Hauge, 1956; Stanbury, 1972). In these three cases the patients died with disseminated metastases, and it is possible that dissemination by the time of the operation may have accounted for the failure to improve. Dent and Gertner (1976) have recently reported three further cases associated with fibrous dysplasia.

The list of histopathological diagnoses in previous cases (Table) shows a very confusing picture regard- ing the nature of the tumours, but as critical reviews have pointed out (Massachusetts General Hospital, 1965; Evans and Azzopardi, 1972; Olefsky et al., 1972; Stanbury, 1972) this may be a difference in semantics rather than a real difference in histogenesis and probably represents an attempt to classify into previously existing categories a tumour that perhaps should stand in a category of its own. In the tumour here reported there were areas which resembled giant cell tumours, fibromatoses, neurilemmomas, osteosarcomas, and chondrosarcomas. Indeed, the true malignant nature of the tumour was apparent only in small fragments of the original biopsy. This pleomorphism has been noted in previous cases. The common denominator of all these tumours is that they are mesenchymal. In some cases a cellular component with scattered osteoclasts appears to predominate, whereas in others there are variable amounts of osteoid, collagen, cartilage, and vascular elements. The name 'pleomorphic mesenchymal tumours associated with osteomalacia' appears suitable until more information becomes available. Electron microscopy confirms the mesenchymal nature of the tumour and the absence of neurosecretory granules, but there are no characteristic features in the cells which may help to elucidate their histogenesis. The recent report of the same type of osteomalacia in a patient with disseminated bone metastases from a prostatic carcinoma (Hosking et al., 1975) introduces new difficulties in the interpretation of the association of hypophosphataemic osteomalacia and neoplasia, but the association in this case could be coincidental.

It is noticeable that in our case the postoperative improvement in inorganic phosphate levels was accompanied by hypercalcaemia.

The cause of this is obscure. Postoperative immobilisation was very brief and thus unlikely to have contributed. Hypervitaminosis D on stopping phosphate therapy is a possibility, but unfortunately it did not prove possible at that time to estimate the plasma $25 \mathrm{OH}$ cholecalciferol. However, the calcium level was not reduced by hydrocortisone which suggests hyperparathyroidism rather than hypervitaminosis $\mathrm{D}$. There was no radiological evidence of hyperparathyroidism; the serum phosphate was normal as was the serum parathyroid hormone. The serumcalcium has returned to normal spontaneously, but the phosphate is now falling and it is not possible to say at this stage whether the remarkable improvement related to the operation will be permanent or whether the fall in serum phosphate heralds a recurrence of the disease. Similar hypercalcaemia has been reported after surgical excision of the tumour in Olefsky's and Pollack's cases (Olefsky et al., 1972; Pöllack et al., 1973). In Olefsky's case 
Table Reported cases of hypophosphataemic osteomalacia associated with mesenchymal tumours of bone or soft tissues

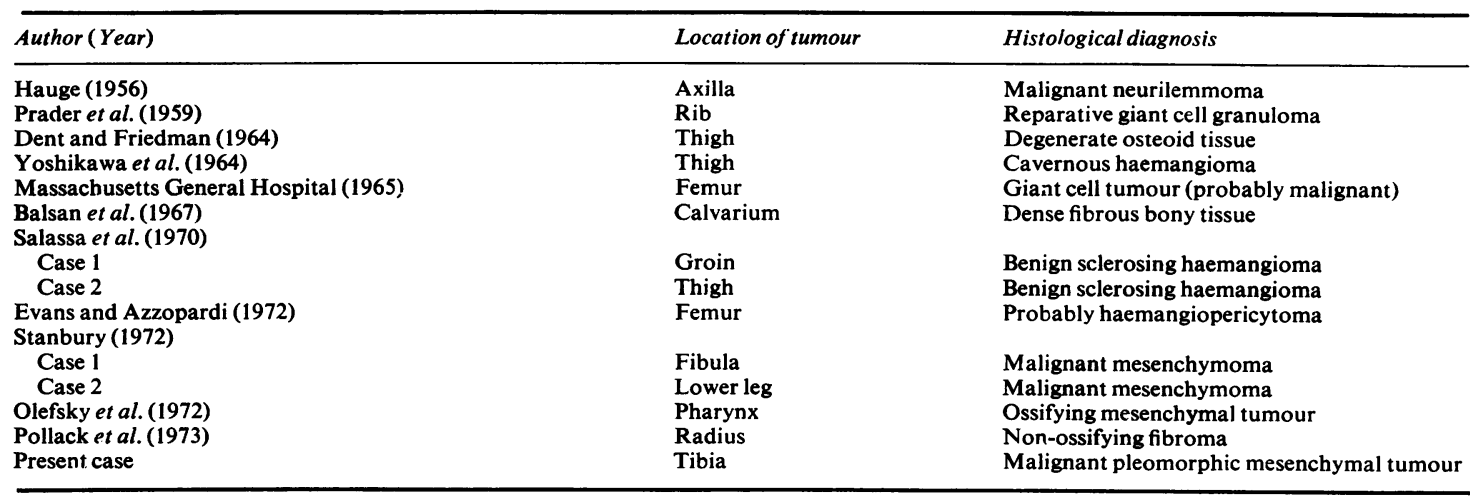

this appeared to be due to 'tertiary' hyperparathyroidism and persisted after removal of a parathyroid 'adenoma', but hypophosphataemia did not recur after five years without treatment. In Pollack's case the follow-up was 18 months and hypercalcaemia was present for only five months after removal of the tumour. It is possible that development of tertiary hyperparathyroidism in these cases, if this is the correct interpretation, may be related to duration of the hypophosphataemia. This was 10 years in Olefsky's case, six years in our case, and three years in Pollack's case.

Rees (1975) has listed six criteria which may be used to establish ectopic hormone secretion, but only two of these, viz, an endocrine abnormality associated with the presence of the tumour and its correction upon removal of the tumour, have been demonstrated in some cases of osteomalacia. In others only the first criterion has applied. The problem is made more difficult because hypophosphataemic osteomalacia is not a sign of oversecretion of any known hormone. The syndrome is therefore not simply a consequence of ectopic hormone production, although its most likely explanation is that the tumour secretes some humoral factor which interferes with renal tubular function.

Hypophosphataemic osteomalacia is a rare disease, and fewer than 30 cases had been reported up to 1971 (Dent and Stamp, 1971). The association of some cases of this type of osteomalacia with tumours, sometimes clinically undetected for many years, makes imperative the careful search for a tumour in every case, since its removal may result in a cure.

We should like to thank Professor H. A. Sissons for help in the interpretation of the histology of this tumour, Professor P. Bordier for his opinion on the bone biopsy, Professor T. C. B. Stamp for the assay of parathyroid hormone, and $\mathrm{Mr}$ J. Strachan, FRCS, for the surgical care of this patient.

\section{References}

Balsan, S., Guivarch, J., Dartois, A. M., and Royer, P. (1967). Rachitisme vitamino-résistant associé à une neuro-fibromatose probable chez un enfant. Arch. franc. Pediat., 24, 609-632.

Dent, C. E. and Friedman, M. (1964). Hypophosphataemic osteomalacia with complete recovery. Brit. med. J., 1, 1676-1679.

Dent, C. E. and Gertner, J. M. (1976). Hypophosphataemic osteomalacia in fibrous dysplasia. Quart. $J$. Med., 45, 411-420.

Dent, C. E. and Stamp, T. C. B. (1971). Hypophosphataemic osteomalacia presenting in adults. Quart. J. 용 Med., 40, 303-329.

Evans, D. J. and Azzopardi, J. G. (1972). Distinctive tumours of bone and soft tissue causing acquired $\dot{\rho}$ vitamin-D-resistant osteomalacia. Lancet, 1, 353-354.

Hauge, B. N. (1956). Vitamin D resistant osteomalacia. Acta med. scand., 153, 271-282.

Hosking, D. J., Chamberlain, M. J., and Shortland-Webb, $\frac{D}{2}$ W. R. (1975). Osteomalacia and carcinoma of prostate with major redistribution of skeletal calcium. Brit. J. N Radiol., 48, 451-456.

McCance, R. A. (1947). Osteomalacia with Looser's $N$ nodes (Milkman's syndrome) due to raised resistance N to vitamin $\mathrm{D}$ acquired about the age of 15 years. Quart.J. Med., 16, 33-46.

Massachusetts General Hospital (1965). Case records. Case 38-1965. New Engl. J. Med., 273, 494-504.

Olefsky, J., Kempson, R., Jones, H., and Reaven, G. (1972). 'Tertiary' hyperparathyroidism and apparent 'cure' of vitamin-D-resistant rickets after removal of an ossifying mesenchymal tumor of the pharynx. New Engl. J. Med., 286, 740-745.

Pollack, J. A., Schiller, A. L., and Crawford, J. D. (1973). Rickets and myopathy cured by removal of a nonossifying fibroma of bone. Pediatrics, 52, 364-371.

Prader, A., Illig, R., Uehlinger, E., and Stalder, G. (1959). 
Rachitis infolge knochentumors. Helv. paediat. Acta, 14, 554-565.

Rees, L. H. (1975). The biosynthesis of hormones by non-endocrine tumours: a review. J. Endocr., 67, 143-175.

Salassa, R. M., Jowsey, J. and Arnaud, C. D. (1970). Hypophosphatemic osteomalacia associated with 'nonendocrine' tumors. New Engl. J. Med., 283, 65-70.

Stanbury, S. W. (1972). Tumour-associated hypophosphataemic osteomalacia and rickets. Clin. Endocr. Metab., 1, 256-259.

Yoshikawa, S., Kawabata, M., Hatsuyama, Y., Hosokawa, O., and Fujita, T. (1964). Atypical vitamin-D resistant osteomalacia. J. Bone Jt Surg., 46A, 998-1007.

\section{The March 1977 Issue}

\section{THE MARCH 1977 ISSUE CONTAINS THE FOLLOWING PAPERS}

Morphology and the natural history of cribriform adenocarcinoma (adenoid cystic carcinoma) D. A. OSBORN

Adrenocortical hyperactivity with disseminated malacoplakia J. MCCLURE, D. R. HADDEN, D. G. MUDD, AND T. G. PARKS

Pre-eclampsia presenting with deep jaundice R. G. LONG, P. J. SCHEUER, AND SHEILA SHERLOCK

Correlations between the detection of e antigen or antibody and electron microscopic pattern of hepatitis B surface antigen (HBsAg) associated particles in the serum of HBsAg carriers C. TREPO, R. G. BIRD, AND A. J. ZUCKERMAN

Modification of factor VIII complex properties in patients with liver disease P. MAISONNEUVE AND YVETTE SULTAN

Myeloproliferative disorders: a paradox of in-vivo and in-vitro platelet function B. J. BOUGHTON, W. E. N. CORBETT, AND A. D. GINSBURG

Megakaryoblastic transformation of chronic granulocytic leukaemia. An electron microscopy and cytochemical study BARBARA BAIN, D. CATOVSKY, MAUREEN O'BRIEN, A. S. D. SPIERS, AND H. G. H. RICHARDS

A population of lymphocytes in human blood distinctive in morphology and other characteristics H. SMITH AND R. J. COLLINS

Polymorphonuclear leucocyte function in Behçet's disease J. D. SOBEL, S. HAIM, N. ObedeANU, T. MESHULAM, AND D. MERZBACH
Cryptococcal meningitis complicating systemic lupus erythematosus: two patients treated with flucytosine and amphotericin B D. C. E. SPELLER, F. FAKUNLE, S. A. CAIRNS, AND MARY STEPHENS

Observations on the use of the double diffusion test in the diagnosis of vaginal candidiasis G. R. JONES AND D. W. WARNOCK

Infection of the foot with Peptococcus magnus P. J. SANDERSON

Processing urinary endoscopes in a low-temperature steam and formaldehyde autoclave G. L. GIBSON

API ZYM: a simple rapid system for the detection of bacterial enzymes M. W. HUMBLE, ANNA KING, AND IAN PHILLIPS

Fucosidosis in a native-born Briton G. B. MacPHEE AND R. W. LOGAN

Zinc and di-iodohydroxyquinoline therapy in acrodermatitis enteropathica MALCOLM J. JACKSON

Technical methods

New disposable plastic syringe for collecting and centrifuging blood PERCY PEREIRA DOS SANTOS

Identification of Gram-negative bacteria in histological sections using Sandiford's counterstain R. E. LEAVER, B. J. EVANS, AND B. CORRIN

Letters to the Editor

Book reviews

Copies are still available and may be obtained from the PUBLISHING MANAGER, BRITISH MEDICAL ASSOCIATION, TAVISTOCK SQUARE, LONDON WC1 9JR, price $£ 2.00$ 